YURI, J.E.; RESENDE, G.M.; MOTA, J.H.; GONÇALVES, L.D.; SOUZA, R.J. Doses e épocas de aplicação de molibdênio na produção e qualidade de alface americana. Horticultura Brasileira, Brasília, v.22, n.3, p. 589-592, jul-set 2004.

\title{
Doses e épocas de aplicação de molibdênio na produção e qualidade de alface americana
}

\author{
Jony E. Yuri' ${ }^{1}$; Geraldo M. de Resende²; José Hortêncio Mota' ${ }^{1}$ Luciano Donizete Gonçalves'; Rovilson \\ José de Souza ${ }^{1}$ \\ 1UFLA, Depto. Agricultura, C. Postal 37, Lavras-MG, E-mail: jonyyuri@ uol.com.br; ²Embrapa Semi-Árido, C.Postal 23, 56300-000 \\ Petrolina-PE
}

\section{RESUMO}

Foram conduzidos três ensaios de dezembro/2001 a fevereiro/ 2002, no município de Nazareno (MG), com o objetivo de avaliar a influência de doses e épocas de aplicação de molibdênio sobre a produção e qualidade de alface americana (Lactuca sativa L.). Utilizou-se o delineamento de blocos ao acaso com cinco doses de molibdênio $\left(0 ; 90 ; 180 ; 240\right.$ e $\left.360 \mathrm{~g} \mathrm{ha}^{-1}\right)$ aplicadas em três épocas via foliar (14; 21 e 28 dias após o transplantio) e 4 repetições. A dose de $235 \mathrm{~g} \mathrm{ha}^{-1}$ de molibdênio proporcionou a maior produção de massa fresca total. Não se observou diferença significativa entre tratamentos para épocas de aplicação. Houve efeito quadrático entre massa fresca comercial e doses de molibdênio, em função das épocas de aplicação, tendo as doses de 236; 212 e $229 \mathrm{~g} \mathrm{ha}^{-1}$ de molibdênio proporcionado as maiores produções comerciais. Verificou-se que a aplicação aos 21 dias após o transplante apresentou as melhores respostas. A dose de $220 \mathrm{~g} \mathrm{ha}^{-1}$ de molibdênio promoveu a maior circunferência da cabeça comercial, sendo que as melhores épocas de aplicação foram aos 14 e 21 dias, que não mostraram diferenças significativas entre si. Não se observou efeito significativo dos tratamentos para comprimento do caule.

Palavras-chave: Lactuca sativa, massa fresca total e comercial, comprimento do caule, circunferência da cabeça comercial.

\begin{abstract}
Response of crisphead lettuce to doses and application times of molibdenum

The influence of molibdenum dosages was evaluated on yield and quality of crisphead lettuce (Lactuca sativa L.). Three trials were carried out in Nazareno, Minas Gerais State, Brazil, from December/ 2001 to February/2002. The experimental design was a randomized complete block with four replications, being evaluated five molibdenum dosages $\left(0 ; 90 ; 180 ; 240\right.$ and $\left.360 \mathrm{~g} \mathrm{ha}^{-1}\right)$ and three application times of foliar-spraying (14; 21 and 28 days after transplanting). The total fresh matter presented quadratic effect where the dosage of $235 \mathrm{~g} \mathrm{ha}^{-1}$ of molybdenum provided the highest yield. Significant differences between treatments were not observed for application times. The commercial fresh matter evidenced quadratic effect when molybdenum dosages were incremented, in function of the application dates. The doses of 236; 212 and $229 \mathrm{~g} \mathrm{ha}^{-1}$ of molybdenum resulted in higher commercial production. The application of molibdenum 21 days after transplanting date showed the best results. Doses of $220 \mathrm{~g} \mathrm{ha}^{-1}$ of molybdenum promoted bigger head circumference, when applied 14 and 21 days after transplanting date. There was no significant difference between treatments for stem length.
\end{abstract}

Keywords: Lactuca sativa, total and commercial fresh matter, stem length, head circumference.

\section{(Recebido para publicação em 16 de abril de 2003 e aceito em 14 de fevereiro de 2004)}

A alface americana, tipo repolhuda crisphead lettuce, vem adquirindo importância crescente, principalmente, na região de Lavras. O plantio deste tipo de alface visa, principalmente, atender as redes fast food, como a McDonald's, com mais de 30 produtores em diversos municípios do sul de Minas Gerais, cultivando cerca de 1800 ha por ano, totalizando aproximadamente 10.500 tdesta folhosa (Yuri, 2000).

Nos sistemas biológicos o molibdênio é constituinte de pelo menos cinco enzimas catalisadoras de reações. Três destas enzimas (redutase do nitrato, nitrogenase e oxidase do sulfito) são encontradas em plantas (Gupta e Lipsett, 1981). A função mais importante do molibdênio nas plantas está relacionada com o metabolismo do nitrogênio, e ligada à ação ou ativação enzimática, principalmente das enzimas nitrogenase e redutase do nitrato (Dechen et al., 1991).

A redutase do nitrato ou nitratoredutase é uma flavoproteína que possui Mo como grupo prostético, cuja síntese é induzida pela presença de Mo e $\mathrm{NO}^{-3}$ no meio (Malavolta, 1980). Esta enzima catalisa a redução biológica do $\mathrm{NO}^{-3} \mathrm{a} \mathrm{NO}^{-2}$, que é o primeiro passo para a incorporação do nitrogênio, como NH2, em proteínas (Dechen et al., 1991). Por outro lado, evita o acúmulo de $\mathrm{NO}^{-3}$ em plantas alimentícias e forragens, impedindo a combinação do mesmo com a hemoglobina do sangue e a produção de meta-hemoglobina que, por não funcionar como transportadora de $\mathrm{O}_{2}$, causa deficiência de oxigênio em pessoas e animais (Malavolta, 1980; Oliveira, 1980). A deficiência de molibdênio em brássicas também está associada a uma acumulação de nitratos nas folhas (Nogueira et al., 1983).

Uma resposta diferencial entre espécies a uma maior disponibilidade de molibdênio tem sido relatada, sendo, de acordo com Malavolta e Kliemann (1985), encontrada alta resposta em alface, brócolos, beterraba, couve-flor, espinafre e repolho.

Respostas positivas à adubação com este nutriente têm sido relatadas com várias culturas, em diferentes países (Gupta e Lipsett, 1981). Entre as olerícolas, couve-flor, brócolis, alface, beterraba, espinafre europeu, nabo e tomateiro se destacam como as culturas mais exigentes (Castellane et al., 1991).

Devido às necessidades extremamente pequenas que as culturas apresen- 


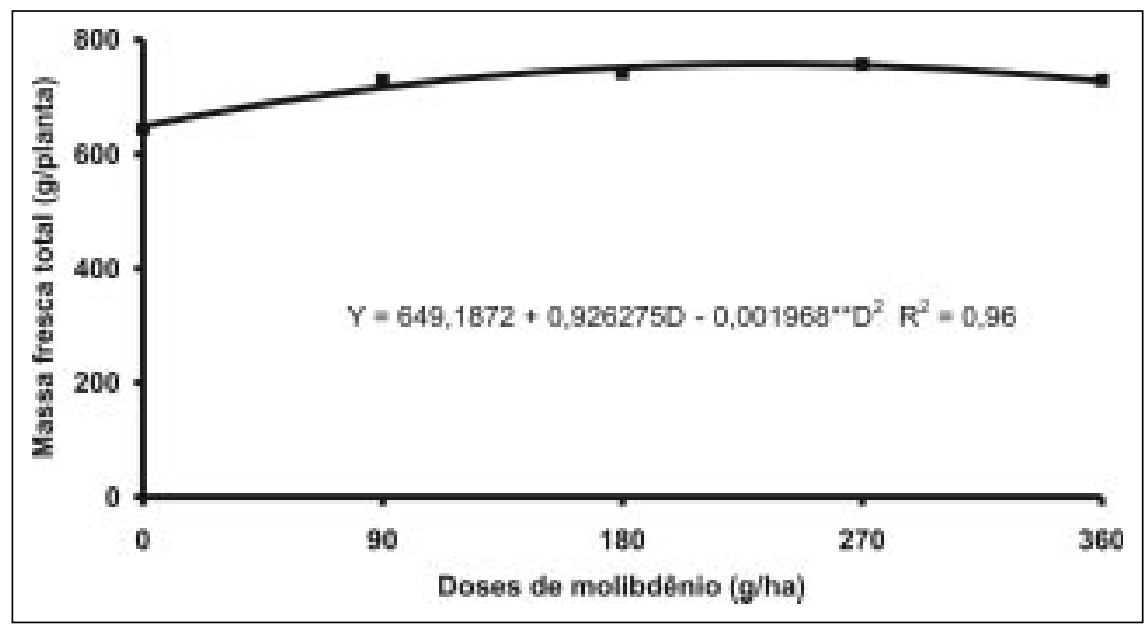

Figura 1. Massa fresca total em função das doses de molibdênio. Nazareno (MG), UFLA, 2001/2002.

tam, Murphy e Walsh (1972) e Gupta e Lipsett (1981) consideram que o fornecimento de molibdênio via semente é a modalidade mais utilizada para suprir as culturas. Segundo estes autores, através da aplicação do molibdenio via semente obtém-se maior uniformidade e eficiência de adubação.

Em alface os sintomas de deficiência de molibdênio começam a aparecer nas folhas amadurecidas que não se desenvolvem bem, permanecendo ovaladas e de cor verde-amarela pálida e mostrando textura semelhante à de papel. Em plantas bem nutridas com nitrato, os sintomas de deficiência de molibdênio assemelham-se aos de nitrogênio. Recomendam-se pulverizar as plantas na sementeira com solução de 0,05\% de molibdato de amônio ou de sódio ou com o produto comercial Cofermol (Sonnenberg, 1998).

No Brasil, poucas são as pesquisas realizadas sobre os efeitos do fornecimento isolado de molibdênio nas produções de culturas olerícolas. Ao que parece, com exceção da espécie Phaseolus vulgaris L., que abrange o feijão de grão e o feijão-de-vagem, os trabalhos publicados envolvendo o uso de molibdênio via semente em espécies olerícolas são muito raros (Castellane $e t$ al., 1991).

Respostas da cultura de alface ao fornecimento de $780 \mathrm{~g} \mathrm{ha}^{-1} \mathrm{de}$ molibdênio via solo, na forma de molibdato de sódio, promovendo um aumento médio de $31 \%$ na produção comercial da cultura foram constatados por Fontes et al. (1982), assim como Zito et al. (1994) verificaram um aumento de $24,1 \%$ na produção comercial de alface com a aplicação de molibdênio.

$\mathrm{Na}$ cultura da couve-flor, em solo com pH 5,3; Novelino e Chaves (1987) verificaram tendência de aumento no acúmulo de matéria seca nas plantas, mediante a aplicação por via foliar de quantidades equivalentes a $24 \mathrm{e} 48 \mathrm{~g} \mathrm{ha}^{-1}$ de Mo. As pulverizações foram realizadas aos 20 e aos 40 dias após a emergência das plantas, fornecendo-se metade daquelas quantidades em cada uma delas.

O presente trabalho teve por objetivo avaliar diferentes doses e épocas de aplicação de molibdênio na produção e qualidade da alface americana em condições de campo.

\section{MATERIAL E MÉTODOS}

Foram conduzidos três ensaios de dezembro/2001 a fevereiro/2002, no município de Nazareno (MG), à altitude de $850 \mathrm{~m}$, com o objetivo de avaliar a influência de doses de molibdênio sobre a produção de alface americana (Lactuca sativa L.). A análise do solo onde foi instalado o experimento apresentou as características: $\mathrm{K}=106,0 \mathrm{mg}$ $\mathrm{dm}^{-3} ; \mathrm{P}=52 \mathrm{mg} \mathrm{dm}^{-3} ; \mathrm{Ca}=4,1 \mathrm{cmolc}$ $\mathrm{dm}^{-3} ; \mathrm{Mg}=0,7 \mathrm{cmolc} \mathrm{dm}^{-3} ; \mathrm{Al}=0,0$ cmolc dm ${ }^{-3} ; \mathrm{H}+\mathrm{Al}=2,3$ cmolc dm $\mathrm{dm}^{-3}$; $\mathrm{Zn}=3,8 \mathrm{mg} \mathrm{dm}^{-3} \mathrm{Mn}=10,0 \mathrm{mg} \mathrm{dm}^{-3} ; \mathrm{B}$ $=1,6 \mathrm{mg} \mathrm{dm}^{-3} ; \mathrm{pH} \mathrm{em} \mathrm{H}_{2} 0=6,0$ e matéria orgânica $=3,4$ dag $\mathrm{kg}^{-1}$.
Utilizou-se o delineamento experimental de blocos ao acaso com cinco doses de molibdênio $(0 ; 90 ; 180 ; 270 \mathrm{e}$ $\left.360 \mathrm{~g} \mathrm{ha}^{-1}\right)$, que corresponderam a 0,0 ; 0,$03 ; 0,06 ; 0,09$ e 1,2\% da solução, aplicada via foliar aos 14; 21 e 28 dias após o transplantio e quatro repetições. As aplicações foliares foram realizadas com pulverizador manual com 4 L de capacidade em máxima pressão, gastandose $300 \mathrm{~L}$ de calda por hectare.

As parcelas experimentais constituíram-se de canteiros com quatro linhas de 2,1 m de comprimento espaçadas de $0,30 \mathrm{~m}$, e $0,35 \mathrm{~m}$ entre plantas. As linhas centrais formaram a área útil, retirando-se duas plantas em cada extremidade. Os canteiros em número de dois eram cobertos por estruturas de proteção (estufa alta, 2,0m de altura). Para a adubação de plantio utilizou-se $1500 \mathrm{~kg}$ $\mathrm{ha}^{-1}$ de formulado 4-14-8 e $1000 \mathrm{~kg} \mathrm{ha}^{-1}$ de superfosfato simples. As adubações de cobertura foram realizadas por meio de fertirrigações diárias, totalizando 40 $\mathrm{kg} \mathrm{ha}^{-1}$ de $\mathrm{N}$ e $85 \mathrm{~kg} \mathrm{ha}^{-1}$ de K, utilizando como fontes uréia e cloreto de potássio até por ocasião da colheita.

O transplantio das mudas com 25 dias de idade foi feito em 07/01/2002, irrigando-se diariamente, sendo a cultura conduzida sob mulching e os demais tratos culturais os comuns à cultura.

As colheitas foram feitas em 21/02/ 2002 sendo avaliadas a massa fresca total e comercial (g planta $\left.{ }^{-1}\right)$; circunferência da cabeça comercial e comprimento do caule da cabeça comercial. Os dados foram submetidos à análise de variância conjunta, sendo as médias comparadas pelo teste de Tukey para épocas de aplicação e regressão polinomial para doses, com base no modelo quadrático, ao nível de $5 \%$ de probabilidade.

\section{RESULTADOS E DISCUSSÃO}

Houve efeito significativo independente para as doses de molibdênio e época de aplicação, assim como para a interação entre estes fatores, variando com as características avaliadas. Para massa fresca total constatou-se efeito quadrático no qual a dose de $235 \mathrm{~g} \mathrm{ha}^{-1}$ de molibdênio proporcionou a maior produção. Não se observou diferenças 
significativas para épocas de aplicação (Figura 1).

Com o incremento das doses de molibdênio, em função das épocas de aplicação (Figura 2), verificou-se efeitos quadráticos para a massa fresca comercial, tendo as doses de 236; 212 e $229 \mathrm{~g} \mathrm{ha}^{-1}$ de molibdênio proporcionado os maiores rendimentos comerciais. A aplicação do molibdênio aos 21 dias após o transplante apresentou as melhores respostas. Resultados positivos da aplicação de molibdênio na cultura da alface são relatados por Fontes et al. (1982) e Zito et al. (1994).

Os fatores estudados apresentaram efeitos independentes para circunferência da cabeça comercial. A dose de 220 $\mathrm{g} \mathrm{ha}^{-1}$ de molibdênio promoveu a maior circunferência da cabeça comercial (Figura 3), sendo que as melhores épocas de aplicação foram aos 14 e 21 dias, sem diferenças significativas entre si. Uma resposta diferencial entre espécies a uma maior disponibilidade de molibdênio tem sido relatada (Malavolta e Kliemann, 1985) em alface, em brócolos, beterraba, couve-flor, espinafre e repolho.

Não se observou efeitos significativos dos tratamentos para comprimento do caule. Esta característica é importante na cultura da alface americana, principalmente, quando destinada à indústria de beneficiamento, devendo ser bastante reduzido para proporcionar menor perda durante o processamento. Caule excessivamente comprido não apresenta boa compacidade e dificulta o beneficiamento, afetando a qualidade final do produto (Yuri et al., 2002).

\section{LITERATURA CITADA}

CASTELLANE, P.D.; SOUZA, A.F.; MESQUITA FILHO, M.D.Culturas olerícolas. In: FERREIRA, M.E. CRUZ, M.C.P. (eds.). Micronutrientes na agricultura. Piracicaba: POTAFOS/ CNPq, 1991. p.549-584.

DECHEN, A.R.; HAAG, H.P.; CARMELLO, Q.A.C. Funções de micronutrientes nas plantas. In: FERREIRA, M.E.; CRUZ. M.C.P. (eds.). $M i$ cronutrientes na agricultura. Piracicaba: POTAFOS/CNPq, 1991. p.65-78.

FONTES, R.R.; LIMA, J.A.; TORRES, A.C.; CARRIJO, O.A. Efeito da aplicação de $\mathrm{Mg}, \mathrm{B}$, $\mathrm{Zn}$ e Mo na produção de alface. Pesquisa Agropecuária Brasileira, Brasília, v.17, n.2, p.171175, 1982.

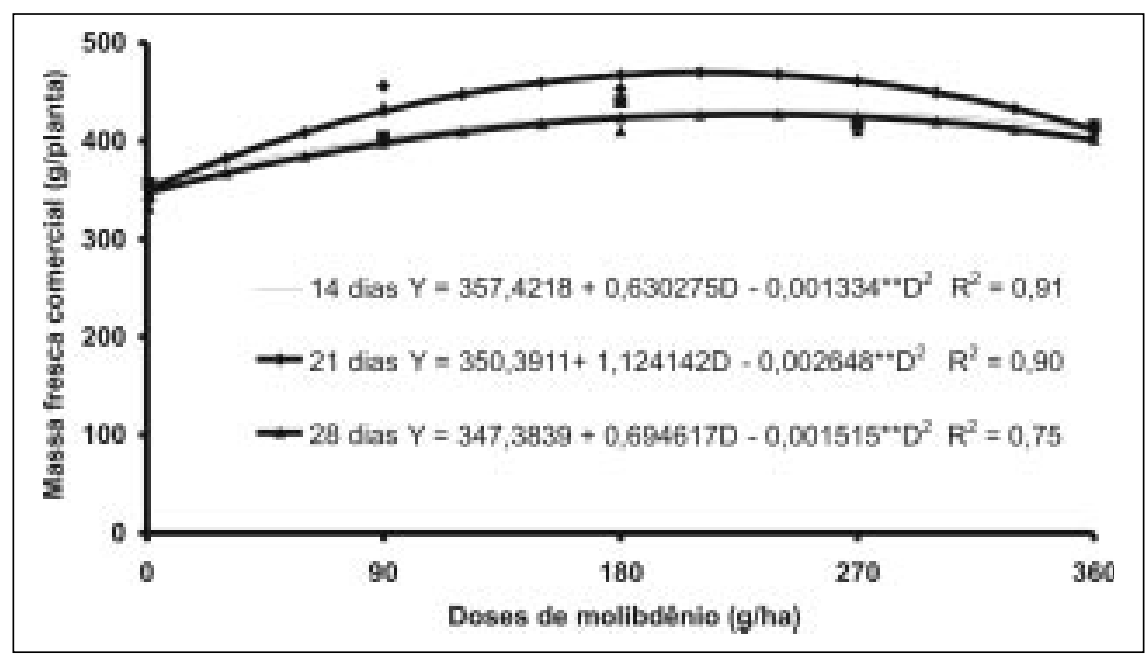

Figura 2. Massa fresca comercial em função das doses e épocas de aplicação de molibdênio. Nazareno (MG), UFLA, 2001/2002.

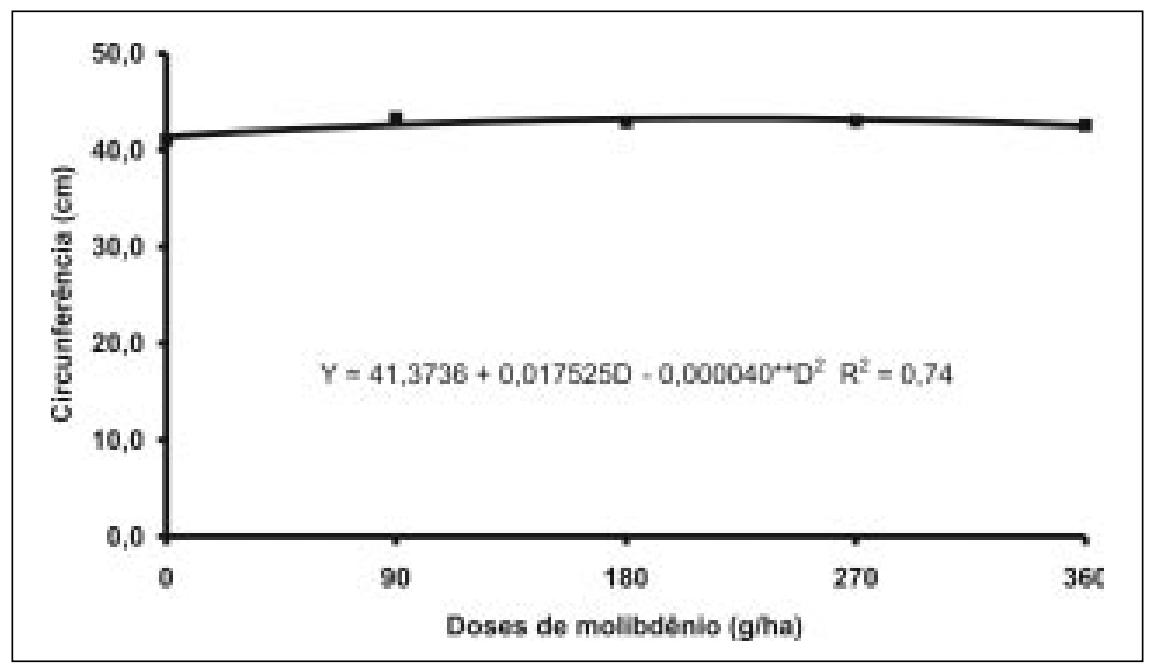

Figura 3. Circunferência da cabeça comercial em função das doses de molibdênio. Nazareno (MG), UFLA, 2001/2002.

Tabela 1. massa fresca total e comercial e circunferência da cabeça comercial em função da época de aplicação. Nazareno (MG), UFLA, 2001/2002.

\begin{tabular}{lccc}
\hline \multirow{2}{*}{ Características } & \multicolumn{3}{c}{$\begin{array}{c}\text { Época de aplicação } \\
\text { (dias após transplantio) }\end{array}$} \\
\cline { 2 - 4 } & $\mathbf{1 4}$ & $\mathbf{2 1}$ & $\mathbf{2 8}$ \\
\hline Massa fresca total (g/planta) & $723 \mathrm{a}$ & $709 \mathrm{a}$ & $730 \mathrm{a}$ \\
Massa fresca comercial (g/planta) & $406 \mathrm{~b}$ & $425 \mathrm{a}$ & $399 \mathrm{~b}$ \\
Circunferência da cabeça comercial $(\mathrm{cm})$ & 42,76 ab & $43,01 \mathrm{a}$ & $41,91 \mathrm{~b}$ \\
\hline
\end{tabular}

${ }^{1}$ Médias seguidas pela mesma letra nas linhas, não diferem entre si, pelo teste de Tukey ao nível de $5 \%$ de probabilidade.

GUPTA, U.C.; LIPSETT, J. Molybdenum in soils, plants, and animals. Advances in Agronomy, New York, v.34, p.73-115, 1982.

MALAVOLTA, E. Elementos de nutrição mineral de plantas. São Paulo: Agronômica Ceres, 1980. 251p.

MALAVOLTA, E.; KLIEMANN, H.J. Desordens nutricionais no cerrado. Piracicaba: POTAFOS, 1985. $136 \mathrm{p}$.
MURPHY, L.S.; WALSH, L.M. Correction of micronutrient deficiencies with fertilizers. In: MORTVEDT, J.J.; GIORDANO, P.M.; LINDSAY, W.L. (eds.). Micronutrients in agriculture. Madison: Soil Science Society of America, 1972. p.347-387.

NOGUEIRA, F.D.; FAQUIN, V.; PAULA, M.B. Solos, calagem e adubação para brássicas. Informe Agropecuário, Belo Horizonte, v.9, n.98, p.2129, 1983. 
NOVELINO, J.O.; CHAVES, J.F. Aplicação de molibdênio e boro em couve-flor. Horticultura Brasileira, Brasília, v.5, n.1, p.68, 1987.

OLIVEIRA, J.P. Efeitos de alumínio e de micronutrientes no feijoeiro (Phaseolus vulgaris L.)

Piracicaba: ESALQ, 1980. 196p. (Tese doutorado) SONNENBERG, P.E. Olericultura Especial $1^{a}$ parte - Alface, Cenoura, Batata, Tomate, Cebola e Alho.Goiânia: UFG, 1998. 184 p.
YURI, J.E. Avaliação de cultivares de alface americana em duas épocas de plantio e dois locais do Sul de minas Gerais. Lavras: UFLA, 2000. 51p. (Tese mestrado).

YURI, J.E.; SOUZA, R.J.; FREITAS, S.A.C.; RODRIGUES JÚNIOR, J.C.; MOTA, J.H. Comportamento de cultivares de alface tipo americana em Boa Esperança. Horticultura Brasileira, Brasília, v.20, n.2, p.229-232, 2002.
ZITO, R.K.; FRONZA, V.; MARTINEZ, H.E.P.; PEREIRA, P.R.G.; FONTES, P.C.R. Fontes de nutrientes, relações nitrato:amônio e molibdênio, em alface (Lactuca sativa) produzida em meio hidropônico. Revista Ceres, Viçosa, v.41, n.236, p.419-430, 1994. 